\title{
An Examination of the Effects of Figure Notes on Sensory Processing and Learning Behaviors on the young children
}

\author{
Liza Lee ${ }^{1}$, Han-Ju Ho ${ }^{2}$, Vasistha Bhargavi ${ }^{3}$ \\ 1,3 Department of Early Childhood Development and Education, Chaoyang University of Technology, Taiwan \\ ${ }^{2}$ Department of Counseling and Educational Psychology, National Taiwan Normal University, Taiwan
}

\begin{abstract}
This study investigates the effects of FigureNotes on sensory processing abilities and the learning behaviors of young children. The settings for this research were a non-profit early-intervention center and a private preschool in the metropolitan, where one hundred and twenty private preschool children and 32 children with Autism Spectrum Disorder, aged 40-63 months, were selected as the research participants by purposive sampling. The research design incorporated HMEAYC with FigureNotes. Each participant participated in one 40-minute session per week for 16 weeks. The research results showed the positive effects of FigureNotes on the children's sensory processing abilities and learning behaviors. The research illustrated FigureNotes not only enhanced visual processing and learning habits in young children, but also enhanced tactile processing in children with Autism Spectrum Disorder (ASD). In this first of its kind, research in Taiwan we propose to prove that FigureNotes can improve young children's visual processing and positive learning habits, and it can enhance the tactile processing of children with ASD. Therefore, we highlight the benefits to promote the use of FigureNotes to assist and support the effective development of young children at different developmental levels.
\end{abstract}

Keywords: Figure Notes, Holistic Music Educational Approach for Young Children (HMEAYC) Children with Autism Spectrum Disorder, Learning behaviors, Sensory-processing abilities

\section{INTRODUCTION}

\section{Research Background and Motivation}

Music has universal and cross-cultural characteristics for the origin of language and symbols, which can trigger memory, arouse emotions and enhance social experience [1]. $65-60 \%$ of human communication comes from non-verbal representations such as pitch, volume, or body posture [2]. This indicates that music, as a non-verbal language, can be used as an auxiliary learning medium for language, cognition and body [3-8]. It is conducive to language, cognition, movement and emotional development [4, 9-11]. In recent years, more attention has been paid to the issue of sensory integration disorder in the behavior of young children. Reports indicate that sensory integration disorder is related to the sensitivity and maturity of the vestibular system [12]. The prevalence rate of sensory integration disorder in 4-6 years old is about 15\% [13]. Moreover, problems in sensory processing will affect daily life and social participation [14-16]. In addition, the Census and Statistics Department of the Ministry of Health and Welfare published 108 years of data on the number of people with physical and mental disorders. It was found that the new category of preschool children aged from three to less than six years did not match the old category and multiple disorders, especially among Children with Autism Spectrum Disorder (ASD) [17]. Studies have shown that children with ASD are significantly different from their peers in their response delay and in their sensation seeking $[18,19]$. Therefore, if children have sensory integration problems, their behavioral responses are not as easily detected, which may negatively affect the opportunity for early treatment. It is suggested that the earlier the detection and treatment, the better will be the therapeutic effect [20]. Providing professional educational resources and medical services for both pre-school and ASD children should be emphasized. Sensory integration therapy for children with ASD is mostly carried out at preschool age or below, and interventions should be adjusted according to individual needs [21-23]. In addition, ASD patients have shown the ability to hear and distinguish timbre [24]. With better long-term memory of tone [25], it can be speculated that using music as the medium can improve the sensory processing and learning behaviors of children with ASD, in general.

Holistic Music Educational Approach for Young Children (HMEAYC) was adopted in Taiwan as a Holistic curriculum

Corresponding Author e-mail: t5190798@cyut.edu.tw https://orcid.org/0000-0002-2966-1334

How to cite this article: Lee L, Ho H, Bhargavi V (2022). An Examination of the Effects of Figure Notes on Sensory Processing and Learning Behaviors on the young children. Pegem Journal of Education and Instruction, Vol. 12, No. 1, 2022, 56-73

Source of support: Nil

Conflict of interest: None.

DOI: $10.47750 /$ pegegog.12.01.07

Received: 09.09.2021

Accepted: 11.11.2021 Publication: 01.01.2022 
model that integrates music education with music therapy. The HMEAYC teaching philosophy has four characteristics [26]. First, Holistic Children may use the holistic approach for children with general and special needs, which is similar to that of a holistic education approach. Second, with a Holistic Field approach, different topics may be integrated. Curriculum design must indicate a holistic approach, consistent with the principles of child development. Third, a holistic faculty should integrate professionals from various fields. The curriculum or activity design utilizes a teaching team approach, which may include the participation of music teachers, rehabilitation teachers (physics, functional and language therapy), specialized teachers and teachers from the elementary school, etc. Fourth, the Holistic Method, HMEAYC is based on the concept of full assimilation and full integration. The study confirms that HMEAYC combines the holistic elements of music with scientific and technological research to enhance the language, attention, physical movement and interpersonal interaction of pre-school children with general and special needs [27-34]. Chinese infant music experts traveled to Finland in 2017 to observe and learn the FigureNotes teaching method [31]; this teaching method is applied to basic education and special education in Finland. The people taught are patients with general and special needs, and the curriculum design is mainly special needs learners [28-34]. By matching color symbols to hear sounds or melodies, this teaching method provides independent learning opportunities to improve learners' confidence and learning motivation [33], as well as joint learning opportunities to achieve a level of music performance ability and enhance social interaction, as well $[35,36]$. Topics and research related to the teaching method of FigureNotes have been published in journals and seminars, such as: development history [39], educational perspectives [37], educational training [38], practice of special education [38], and application of rehabilitation therapy [39]. From professional experience, this approach combines Orff's music rhythm teaching method [32] with Story composing [39]. The teaching method of FigurNotes is still a new music teaching model in Taiwan, which will require more rigorous research to prove its applicability across Taiwan's educational environment. Aforesaid mentioned HMEAYC and FigurNotes music teaching method have a similar education point of view, this research tries to compare and cross references areas of HMEAYC characteristics with "multimode" (two or more) teaching methods. Among the areas of comparison are learning concepts fusion design of HMEAYC with FigurNotes and music teaching of preschool in general, and the sense of ASD children and the effect of learning behavior and their learning process. The purposes of this study: 1 . to explore the effect of FigurNotes music teaching on preschool children's sensory processing and learning behavior. 2. to understand the learning process of FigurNotes music teaching with preschool children's sensory processing and learning behavior.

\section{Nouns Defined}

1. FigureNotes teaching method: the study refers to the teaching method of FigurNotes, which was proposed by Finnish music educator Kaarlo Uusitalo to use visual pairing to connect graphics and color symbols $[33,34]$. This teaching method is characterized by allowing learners to match specific color patterns of atonal or tonal instruments to express sound or play melody as an auxiliary tool for learning or teaching [33].

2. Young Children: The children referred to in the study are "young children" who are enrolled in kindergartens and children with Autism Spectrum Disorder (ASD), who have a medical diagnosis certificate issued by an early treatment institution. Article 12 of the "Measures for Identification" of students with physical and mental disorders and gifted students, the term "Autism" as mentioned in paragraph 11 of Article 3 of the Act refers to a person who has clinically identified problems in communication, social interaction, behavior and expression of interest. It is due to neuropsychological dysfunction and also has significant difficulties with learning and adapting to life." Age: generally, children with ASD are diagnosed and identified between 43 and 61 months of age.

3. Sensory Processing: Sensory processing is the behavioral and emotional responses affected by the functions of the body's sensory system, sensory adjustment and sensory processing. The idea is that sensory processing is: auditory processing, visual processing, and tactile processing. Research tools use the "Sensory Processing Analysis Scale. This scale is provided to preschool classes for teachers and observers. Its values include an original score based upon a score in reading. Performance levels are described as normal functioning - normal sensory processing, "edge" for sensory processing suspecting there is a problem, and "obstacle", there is something wrong with the function of sensory processing [40].

4. Learning Behaviors: Learning behaviors can result in a child's good learning performance and contribute to advancing learning skills, attitudes, habits and results. A teacher rating scale based on the Social Behavior Assessment System for preschool children was used as a research tool. The study refers to learning behaviors by the descriptors: "Learning Habits" and "Learning Performance". The scale was provided by preschool teachers and observers, and its value was presented by the original score. The score of the scale was interpreted as the more questions that measured the degree of conformity, the better the learning behavior of children. 


\section{LITERATURE REVIEW}

\section{The Development History and Current Situation of the Teaching Method of Figurenotes}

FigureNotes, which is also popularly known as Image Note Music Teaching Method (INMTM) was proposed by Finnish music educator Kaarlo Uusitalo in 1996, and actively promoted and applied by Petri Lehikoinen and Markku Kaikkonen in the field of music education in Finland [35]. This pedagogy became a part of formal music education practice throughout Finland in 2004, and it formally received financial support from the government. In 2009, it was incorporated into curriculum design of basic education and special education in Finland. This teaching method represents various sounds through matching graphics and colors, such as visual simplified notation system figure 1[35]; these can be used with piano, keyboard and other instruments $[33,34]$. This teaching method is designed for learners who are interested in music as a tool for them to create and express music $[32,34]$. Extremely tolerant and resilient [37,38], it can be used as a tool to develop individual or group musical ability and assist in achieving rehabilitation therapy goals [49].

\section{The Present Situation and Application Effect of HMEAYC in Taiwan}

Holistic Music Educational Approach for Young Children (HMEAYC) has been promoted intensively since 2012 in Taiwan, for the purpose of using teaching activities that contribute to the holistic development of children, and implementing a curriculum that integrates traditional musical instruments, technological instruments and multi-sensory devices [42]. The teaching structure includes a hello song, attendance song, nursery rhyme time, musical game, musical storytelling, music appreciation, relaxation time and goodbye song, etc. Instruction can be flexibly reduced or repeated during the teaching of instruction. Studies have found that HMEAYC has positive effects on general children's learning and similar effects on children with special $[32,33]$. Examples of positive effects are: language, attention, body movements $[26,27]$ and interpersonal interactions [56]. In the multisensory environment $[31,32]$, the integration of scientific and

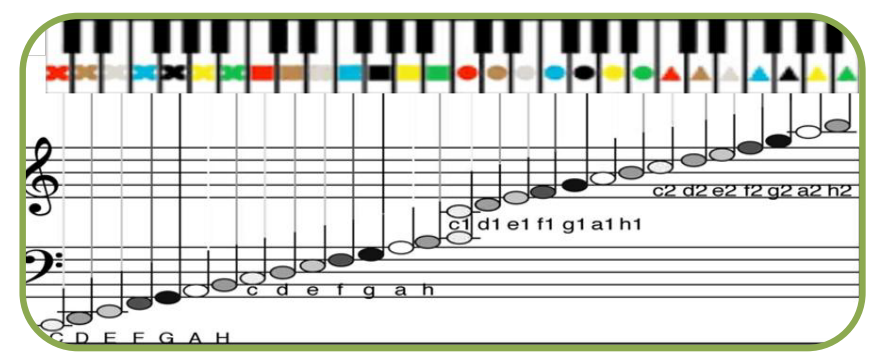

Fig. 1: Staff diagram of musical teaching method of FigureNotes technological instruments [33], such as Soundbeam [28,43,], has also shown positive significant learning effects. It can improve language, body movements and attention span of children with ASD $[28,44]$.

\section{Study on Sensory Processing and Learning Behavior In Preschool Children}

Preschool children often exhibit hyperactivity, attention deficit and emotional instability, which may not be integrated into group learning. Therefore, understanding preschool children's sensory processing is an important issue in curriculum design. The vestibular system is at the core of motor development, and it is related to the development of body balance and hand-eye coordination $[13,43]$. In case of sensory integration disorder, there may be two extreme reactions: hypersensitivity to sound or hypersensitivity to some sounds, as indicated by covering one's ears or screaming [12]. Children with weak sensory processing may have slower motor responses and poor sense of balance, or even meaningless behavioral manifestations, which are all related to poor functioning of the sensory system [44]. Therefore, early detection of sensory integration disorders and early treatment will help improve sensory integration, promote movement and improve overall learning. Autism Spectrum Disorder (ASD) is a lifelong neuro-developmental disorder, in which an individual may exhibit normality in vision and hearing but is prone to repetitive or stereotypical behaviors [45-48]. There are language expression problems as well such as explicit tactile defenses [45, 49-51]. Children with ASD have atypical sensory processing $[15,52]$. The incidence is not consistent with a defined age of presentation $[18,66]$. However, the extreme range of children with ASD is characterized by early onset [58]. In these cases, the incidence of sensory overresponsiveness was higher than that of ordinary children, and it was more likely to occur in the presence of unexpected or annoying irritation $[59,60]$. Studies have found that children with ASD have significant sensation in sensory input processes such as hearing, touch, vestibular and proprioception $[14,15,18]$, or an unexpected stimulus to the environment, thereby resulting in a display of tactile defensiveness. Additional recreational activities indicate that children with ASD have a limited level of participation, and their social, behavioral and informal activities may be associated with atypical sensory processing and low level of participation [61]. Most of the patients' activities were confined to their homes [16]. It can be speculated that it is related to sensory processing of dullness or hyperesthesia $[14,15]$. Studies on vision have found that graphic symbols are a good decoding or media tool [62]. It has a positive effect on learning [63-65]. In particular, research shows they could improve the communication and recognition ability of children with special needs $[62,64,65,66]$. This study found that the children with ASD were assisted through speech therapy, communication aids, electronic communication 
devices, picture or drawing aids and other tools [68]. Other strategies include oral training for audio-visual interaction [69], participation in self-activity [52], autonomous body control and active imitation [28]. Therefore, it is speculated that improving the sensory processing of children with ASD may help children to control their body and imitate positive behaviors, as well as with their communication and social interaction abilities.

\section{Research Methods}

The experimental group and the control group receives HMEAYC, however, only the experimental group was involved in the Image Note Music Teaching Method (INMTM). This was in order to understand whether there is a relationship (isolate a variable) between the use of image note music teaching method and sensory processing and learning behavior, and to further explore its effectiveness.

\section{Research Site and Object}

In this study, 120 pre-school children in kindergarten and 32 children with Autism Spectrum Disorder (ASD), in a non-profit early intervention center, were selected as subjects with the intention of sampling. Both groups were aged 43 to 61 months. The curriculum for both institutions is similar to the classroom setting (both have study corners). The gross motor performance and fine motor performance of preschool children were in line with age development, and the visual, auditory and motor performance were normal. With the not for profit early intervention service all licensed certificate of diagnosis, children diagnosed with autism spectrum disorder children, visual and auditory all normal, action performance can be mostly running and jumping, but balance is insufficient, part of the onset of the overall strength and pose transformation ability is insufficient, the learning process has obvious social interaction (tactile defense) (no eye contact) and communication difficulties. Table 1 shows the results of language $(\mathrm{x} 2=13.16, \mathrm{p}>.05)$, society $(\mathrm{x} 2=13.19, \mathrm{p}>.05)$, and motor skills $(\mathrm{x} 2=2.02, \mathrm{p}>.05)$ of the adaptive behavior assessment system (ABAS -- II). The experimental group and the control group had 60 children, and their language, emotional, social and motor development were similar. "Language (x2=7.85, p>.05)", "social (x $2=8.58, \mathrm{p}>.05)$ ", "motor skills ( $\mathrm{x} 2=3.76, \mathrm{p}>.05)$ ), "language, emotion, social and motor development of children with ASD were homogeneous in 17 subjects and 15 subjects in the control group.

\section{Study Design}

Research needs to coordinate with children selected and randomly assigned to the course: 1 . In order to avoid interference with a quasi-experimental study, and not the design group both before and after testing (quasi - experimental nonequivalent control group design), 2. the experimental group and control group of the same group of research; the set in the control group may change over time as the object of considerations involved in development, and 3. Planning, age and barrier type homogenous children do reference comparison. Two control groups of preschool children and children with ASD were set up in order to understand the relationship between sensory processing and learning behavior and to explore whether or not there is a significant difference between the experimental group and the control group after the intervention of image music teaching. The self-variable was the manipulative variable of the study. The experimental group receives HMEAYC in combination with the teaching method of FigureNotes and music, while the control group receives HMEAYC only. The dependent variable was sensory processing and learning behavior. There are three professional roles in the teaching site: teacher, collaborative teacher and class teacher.

Table 1: Children's basic data distribution column table

\begin{tabular}{|c|c|c|c|c|c|c|c|c|c|c|}
\hline \multirow[t]{2}{*}{ Project } & \multicolumn{4}{|c|}{ General early childhood } & & \multicolumn{5}{|c|}{ Children with Autism Spectrum Disorder (ASD) } \\
\hline & \multicolumn{2}{|c|}{$\begin{array}{l}\text { Experimental } \\
\text { group }(N=60)\end{array}$} & \multicolumn{3}{|c|}{$\begin{array}{l}\text { Control group } \\
(N=60)\end{array}$} & \multicolumn{2}{|c|}{$\begin{array}{l}\text { Experimental group } \\
(N=17)\end{array}$} & \multicolumn{3}{|c|}{ Control group $(N=15)$} \\
\hline \multicolumn{11}{|l|}{ Gender } \\
\hline Boy & 29 & & 32 & & & 12 & & 11 & & \\
\hline Girl & 31 & & 28 & & & 5 & & 4 & & \\
\hline Months of age & $43-61$ & & $44-60$ & & & $43-61$ & & $43-61$ & & \\
\hline $\begin{array}{l}\text { Assessment of } \\
\text { the project }\end{array}$ & $\begin{array}{l}\text { The } \\
\text { average }\end{array}$ & $\begin{array}{l}\text { The } \\
\text { standard } \\
\text { deviation }\end{array}$ & $\begin{array}{l}\text { The } \\
\text { average }\end{array}$ & $\begin{array}{l}\text { The } \\
\text { standard } \\
\text { deviation }\end{array}$ & & $\begin{array}{l}\text { The } \\
\text { average }\end{array}$ & $\begin{array}{l}\text { The } \\
\text { standard } \\
\text { deviation }\end{array}$ & $\begin{array}{l}\text { The } \\
\text { average }\end{array}$ & $\begin{array}{l}\text { The } \\
\text { standard } \\
\text { deviation }\end{array}$ & \\
\hline Language & 88.58 & 10.81 & 88.50 & 11.25 & $\mathrm{X} 2=13.16, \mathrm{P}>05$ & 16.18 & 4.18 & 16.67 & 3.90 & $\mathrm{X} 2=7.85, \mathrm{P}>.05$ \\
\hline Social & 68.93 & 4.66 & 68.93 & 4.61 & $\mathrm{X} 2=13.39, \mathrm{P}>.05$ & 20.65 & 3.28 & 21.33 & 2.69 & $\mathrm{X} 2=8.58, \mathrm{P}>.05$ \\
\hline $\begin{array}{l}\text { Movement } \\
\text { skills }\end{array}$ & 76.07 & 4.51 & 76.35 & 4.24 & $\mathrm{X} 2=! 2.02, \mathrm{P}>.05$ & 52.47 & 9.46 & 53.60 & 8.36 & $\mathrm{X} 2=3.76, \mathrm{P}>.05$ \\
\hline
\end{tabular}


The teacher is a qualified 0-6 music teacher and music therapist in the United States. The collaborative teacher and class teacher are from the department of early childhood education or special education and have received professional training from HMEAYC for more than half a year. Additionally, observers did not enter the classroom for post-mortem video analysis. All the participants (class teachers and observers) participated in two special education workshops. First was the "Pre-school Children's Social Behavior Assessment System (2017.9.25)" workshop, and it was conducted to learn the implementation method and result interpretation of the pre-school children's social behavior Assessment system. Second was the study of "Sensory integration applied to the assessment and Treatment of autistic children (December 11, 2016)", which aimed to evaluate sensory integration function. The following research procedures are described:

1. A pretest (O1) : no teaching before the test, this phase has a "sensory processing analysis scale" and "preschool children's social behavior evaluation system", two tests were given for all participants in the study by the classroom teacher for children. At the same time participants also became familiar with the evaluation of children on a daily basis in order to adapt to the skills of parents or caregivers to fill in the "adaptive behavior evaluation system. (Second edition ABAS - II). Observers are expected to collect the object of study of language, social and motor skills and basic data (Table 1); the purpose is to understand the object of study development status after the design is suitably defined for the course.

2. Treatment period $(\mathrm{O} 2)$ : In the treatment period, both the experimental group and the control group participated in HMEAYC, and only the experimental group accepted the teaching method of FigureNotes. This was done once a week for 40 minutes for 16 weeks. The courses include: hello songs, attendance songs, singing activities, musical stories, music rhythm, relaxation time and goodbye songs (Lee, 2016). During the processing period, the class teacher and the observer recorded the behavior with the HMEAYC observation table.

3. Posttest (O3): After 16 weeks, the teacher of the class will evaluate the "Sensory Processing analysis Scale" and the "Preschool Children's Social Behavior Assessment System", in order to obtain the learning effect presented by the teaching method whether the study objects have been exposed to FigureNotes and music.

\section{Research Tools}

The research tools include: the quantitative data of "adaptive Behavior Assessment System, the Sensory Processing Analysis Scale, the Social behavior Assessment System for Preschool Children, and qualitative data from the "HMEAYC Observation Table". Instruments and teaching materials were provided by the research team.
1. Adaptive Behavior Assessment System Second Edition (ABAS - II) : Second Edition adaptation evaluation System for Lu-hua (translation by Professor Hsin-yi of the Adaptive behaviors Assessment System - Second Edition, Forsblom ABAS). This provides the basis for standardization of individual testing and evaluation data by team members familiar with each student. Evaluation of each child's daily log of performance and behaviors is done in order to adapt instructional strategies to the skills of parents, teachers or other contact persons. Each helps fill in the applicable objects for 48-71 month old students. The content covers the functions of communication, pre-school, self-direction, leisure, social, family, social application/ school life, health and safety, taking care of yourself, and action skills. The scale has good reliability (internal consistency $.98 \sim .99$, subscale average reliability $.91+$ ) and construction validity [72]. Only three subscales were used in the study are: "conceptual knowledge communication" question 25, "social knowledge - social interaction" question 24 and "action skills" question 27. These were selected to understand the basic linguistic, social and behavioral development of the subjects before the study, as well as whether the subjects are homogeneous in the same variation. The data sources are provided by parents or caregivers who are familiar with the assessed child's daily adjustment skills.

2. Sensory Profile: This scale, developed by Dr. Dunn (1999) in the United States, is applicable to the evaluation of Sensory processing in children aged 3 to 10 years; the Chinese version was used in this study [41]. The Sensory Processing Analysis Scale has three components: the first is sensory processing: to understand children's sensory input processing process and behavioral response. There are six kinds of sensation: auditory, visual, vestibular, tactile, multi-sensory, and oral. Second is sensory regulation: to understand children's neural information regulation and organizational capacity, including muscle endurance and tension, body posture, movement and activity. The third one is emotional response: to explore children's emotional and social response, sensory processing behavior. The full scale showed good reliability, with an intrinsic reliability of.62 .90, and a retest reliability of 0.93 , auditory subscale of 0.75 , visual subscale of 0.85 , tactile subscale of 0.86 , activity subscale of 0.78 , taste/smell subscale of 0.79 , body posture subscale of 0.80 , action subscale of 0.83 , and emotional/social subscale of 0.92 . In this study, only auditory, visual and tactile processing were selected for analyzing the sensory processing performance of children. The source of the data is the assessment data provided by the class teacher.

3. Social Behavior Assessment System for Preschool And Preschool (SBASP): This scale is a multi-dimensional 
standardized scale applicable to the Social Behavior Assessment of Preschool children aged 4 to 6 years [80]. Selected were the Teacher Rating Scale (TRS) and the Parent Rating Scale (PRS) [74,75]. Social competence is divided into two categories: the first includes selfcontrol (autonomous behavior, emotion management), interpersonal interactions (interpersonal relationship, communication, expression, and cooperative empathy) and learning behaviors (learning habits, learning performance). Secondly, "problem behaviors" are: distraction and overactivity (unfocused, overactive and impulsive), resisting and violating rules (angry and resisting, attacking and violating rules) and anxious and withdrawn (anxious and afraid, withdrawing shy and physical and mental symptoms). On the scale, the social competence reliability was .57 .89, and the problem behavior reliability was .38 .90 [80-82]. In order to understand children's participatory learning behaviors, only the "learning habits and learning performance" of social competence learning behaviors on the teacher rating scale were selected for analysis. The source of the data is the assessment data provided by the class teacher.

4. HMEAYC Observation Table: This is a self-compiled, semi-structured observation record table for class teachers and observers (see Table 2). The study used only the data recorded in the behavioral records section for coding analysis, which was then supplemented by qualitative data for supplement quantitative analysis.

\section{Data Processing and Analysis}

A total of 16 records were collected from the pretest and posttest data of sensory processing and learning behavior. In

Table 2: HMEAYC observation is an example

\begin{tabular}{|c|c|c|c|c|c|c|c|c|}
\hline $\begin{array}{l}\text { Experimental } \\
\text { group }\end{array}$ & & $\begin{array}{l}\text { Children's } \\
\text { number }\end{array}$ & The observer & QThe teacher & $\square \mathrm{Ob}$ & ervers & & \\
\hline $\begin{array}{l}\text { Observation } \\
\text { week }\end{array}$ & & & $\begin{array}{l}\text { Observation } \\
\text { date }\end{array}$ & & & & & \\
\hline Activity items & $\begin{array}{l}\text { Observed } \\
\text { variables }\end{array}$ & Content & & $\begin{array}{l}\text { There is } \\
\text { no }\end{array}$ & Very few & $\begin{array}{l}\text { Once in a } \\
\text { while }\end{array}$ & Often & Always \\
\hline \multirow[t]{2}{*}{ Hello song } & $\begin{array}{l}\text { Auditory } \\
\text { processing }\end{array}$ & $\begin{array}{l}\text { 1. Able to respond to the teacher } \\
\text { movements. }\end{array}$ & with body & 1 & 2 & 3 & 4 & 5 \\
\hline & & Behavior Record: & & & & & & \\
\hline
\end{tabular}

Table 3: Coded instructions.

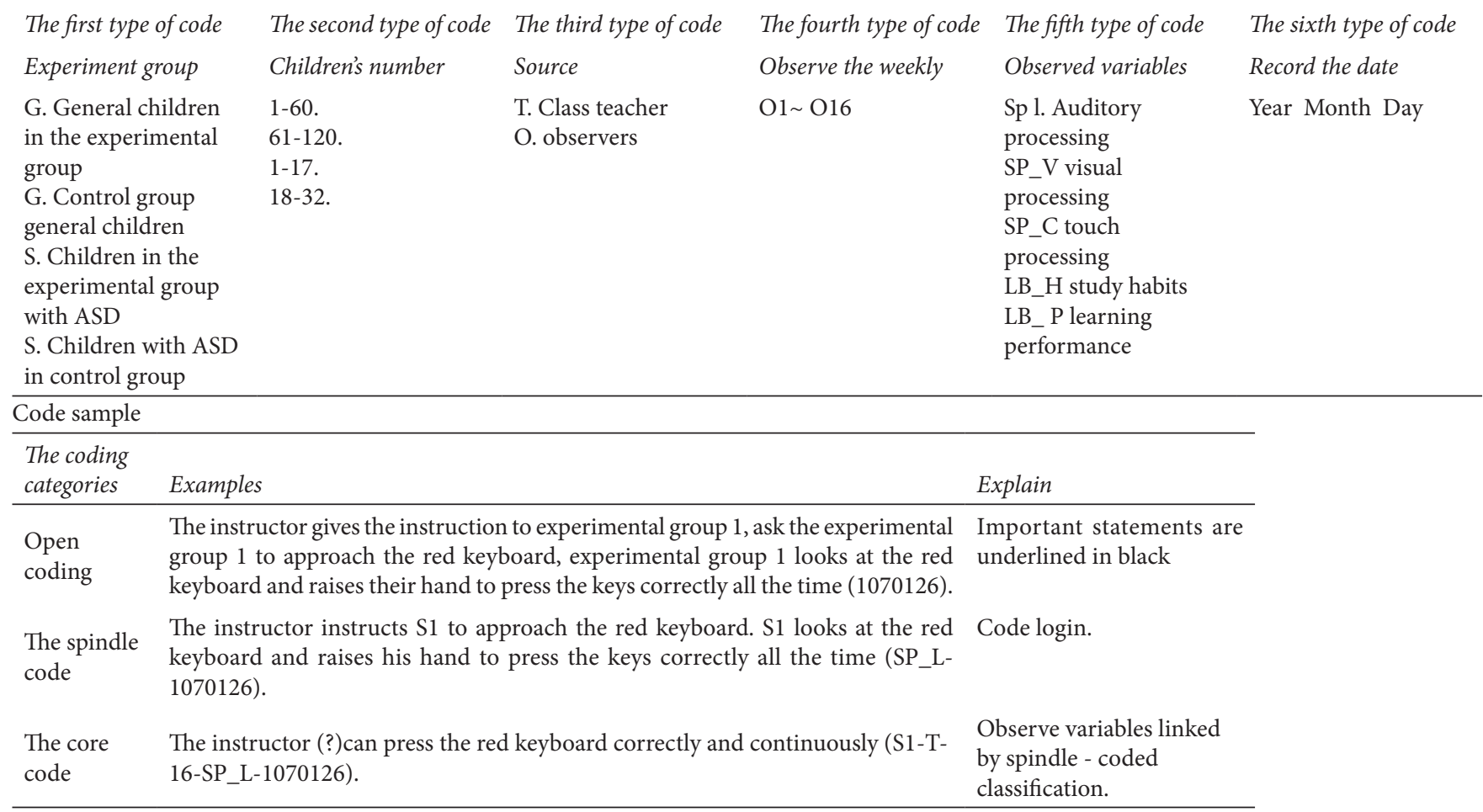


order to avoid the interference of other factors, the factors that could affect the process and outcome of the intervention were controlled. First, the changes of the experimental group and the control group before and after intervention were observed by a T-test. Second, a significant difference was found between the experimental group and the control group in the post-test of sensory processing and learning behavior. The pre-test score was a common variable, and the difference between the pre-test score and the post-test score was the intervention effect. Finally, the study records of "sensory processing" and "learning behavior" were analyzed. Table 3 is the HMEAYC observation table. In order to present qualitative data and supplement the meaning of quantitative data, the following is the coding description:

Experiment groups with children's number "G1 - G60 will be (?). As an infant, the experimental group, G61 - G120. As an infant, the control group, S1 - S17. Experimental ASD children, S18 - S32. Control group ASD children", the source "observer" t. class teachers, O, observation weekly "O1 to O16. Observe weekly", observed variables "(SP_L. Auditory processing, SP_V visual processing, processing, LB_H SP_C touch learning habits, LB_P academic performance", recording date (date). Example: G5-T-03-SP_L-1071007 is the experimental group No. 5 general Children - class teacher - Week 3- Auditory processing - October 07, 107. Coding example shows that the coding marks the important text description with open coding, then the homogeneous concepts in the spindle coding are classified, and the generic concepts are logged according to the data coding.

\section{Study Reliability and Validity}

1. Peer review: Study peer review was conducted by using triangulation to interactively check the login time data for the same phenomenon. This was done in order to improve the reliability of the results and reduce bias and error [76].

2. Multiple perspectives: Professional teams are composed of teachers, collaborative teachers, class teachers, physiotherapists and observers. HMEAYC and image music teaching methods are implemented by the teachers, and the collaborative teachers assist with the teaching. During the study, the teachers and the collaborative teachers discuss the course (regularly or as needed) and adjust the course contents in a timely manner.

3. Between coders reliability: In the research field, all professional personnel should be required to have strict training and practice records login skills, if raters reliability is lower than 0.6 following a review analysis of evaluation content, this will prompt a discussion for correction and consensus, the registration for overall analysis and interpretation. Regarding observation, a common standard established coding, based on reliability, is expected to have a consistency between the observers as in table 4; generally, children's group consistency shall be in a range of $72.8 \%-88.9 \%$, with the ASD children's group consistency in a range of $64.5 \%$ to $87.1 \%$.

4. Ecological validity: A fixed camera and two sets of action photography were set up in the research setting to master the overall dynamic images, hoping to provide multiple visual angles for better interpretation of observed phenomena [76,77].

5. Intrinsic validity: The quantitative data included the data collected by the class teacher before and after the test, and the qualitative data provided the observer with 16 HMEAYC observation records. It was expected that the research would present an overall summary analysis of the quantitative and qualitative mix, so as to improve the intrinsic validity.

\section{Research Analysis and Results}

There were 60 children in the general control group and the experimental group, a total of 120 children, and 17 children in the ASD control group and 15 children in the control group, a total of 32 children. As an infant (do you mean test or control group ?), to understand ASD sensory processing, in the two groups of children with learning behaviors and in an effort to determine whether there are differences, table 5 presents two sets of the mean: standard deviation of the test before and after the test and $t$ test, table 6 and table 7 for young children with ASD children group general single factor variable analysis. Then as an infant (?), data was presented for the ASD children group for sensory processing and record learning behavior analysis.

\section{Single Factor Covariate Analysis of Regular Children Group and ASD Group}

To understand young children with ASD children group general sensory processing and learning behavior in studying whether recent homogeneity. Respectively, there is general feeling (?) of children with ASD in the two groups of children

Table 4: Interobserver consistency

\begin{tabular}{llllll}
\hline & \multicolumn{1}{c}{ Sensory processing } & \multicolumn{2}{c}{ Learning behavior } \\
\hline The reliability(\%) & Auditory processing & Visual processing & Tactile processing & Study habits & Academic performance \\
\hline General Child Group & $88.9 \%$ & $74.4 \%$ & $72.8 \%$ & $87.7 \%$ & $73.2 \%$ \\
ASD children group & $87.1 \%$ & $77.1 \%$ & $72.6 \%$ & $70.0 \%$ & $64.5 \%$ \\
\hline
\end{tabular}


with learning behavior test before $t$ test, as an infant, table 5 for the group of auditory processing $(\mathrm{t}=0.21, \mathrm{p}>.05)$, visual treatment $(\mathrm{t}=1.20, \mathrm{p}>.05)$, touch treatment $(\mathrm{t}=.95, \mathrm{p}>.05)$, as an infant, according to sensory processing in the group could be the same; Auditory processing ( $\mathrm{t}=1.52, \mathrm{p}>.05$ ), visual processing $(\mathrm{t}=-.13, \mathrm{p}>.05)$, and tactile processing $(\mathrm{t}=-$ $.13, \mathrm{p}>.05)$ in children with ASD showed that the sensory processing in children with ASD might be homogeneous. Secondly, "learning habits $(\mathrm{t}=.00, \mathrm{p}>.05)$ " and "learning performance $(\mathrm{t}=-.49, \mathrm{p}>.05)$ " in the general infant group showed that learning behaviors in the general infant group might be the same. "Learning habits $(\mathrm{t}=.43, \mathrm{p}>.05)$ " and learning performance ( $\mathrm{t}=-1.77, \mathrm{p}>.05)$ "in the ASD group indicated that learning behaviors in the ASD group might be homogeneous. On the whole, the sensory processing and learning behaviors in the general children's group and the ASD infant group were not statistically significant, so it is speculated that there is a degree of homogeneity between the two groups in this study.

\section{Single factor covariate analysis of "sensory processing" and "learning behavior" in general children group}

As an infant, Table 6 - showing the set of single factor variables analysis results - ruled out use of pre-test scores (variable) and indicated visual processing having an extremely significant difference ( $F$ value is $7.99, \mathrm{p}<.01$ ). This was shown after the event was found in the control group and after measuring the average is 28.92. In contrast, the experimental group measured averages of 29.65, according to the experimental group after measuring the average higher than the control group. This illustrates the general group of visual processing is followed by measuring results for acceptance when the intervention treatment is different, as an infant. This speculates that the group image notes from the music teaching method have significant effects on the visual processing. Additionaly for the experimental group and control group, the score of the study habits show a significant difference (according to the experimental group has effect on intervention ( $F$ value is 6.28, $\mathrm{p}<.05)$. After the event is found in the control group and after measuring the average is 21.07 , the experimental group measured averages of 21.98, as an infant; an inference is that the FigureNotes teaching method from its use in the study promotes visual processing.

\section{Single factor covariate analysis of "sensory processing" and "learning behavior" in ASD group}

Table 7. Variables for the ASD children set of single factor analysis results, excluding the impact of a pre-test score

Table 5: Mean, standard deviation and $\mathrm{T}$ tests of sensory processing and learning in general and ASD children.

\begin{tabular}{|c|c|c|c|c|c|c|c|c|c|c|c|c|}
\hline \multirow[b]{3}{*}{ Category } & \multirow[b]{3}{*}{ Test content } & \multirow[b]{3}{*}{$\begin{array}{l}\text { To deal } \\
\text { with }\end{array}$} & \multicolumn{5}{|c|}{ General early childhood $(N=120)$} & \multicolumn{5}{|c|}{ ASD children $(N=32)$} \\
\hline & & & \multicolumn{2}{|c|}{$\begin{array}{l}\text { Experimental group } \\
(N=60)\end{array}$} & \multicolumn{2}{|c|}{$\begin{array}{l}\text { Control group } \\
(N=60)\end{array}$} & \multirow[b]{2}{*}{$\begin{array}{l}t \text { verifi } \\
\text { cation }\end{array}$} & \multicolumn{2}{|c|}{$\begin{array}{l}\text { Experimental group } \\
(N=17)\end{array}$} & \multicolumn{2}{|c|}{$\begin{array}{l}\text { Control group } \\
(N=15)\end{array}$} & \multirow[b]{2}{*}{$\begin{array}{l}t \text { verifi- } \\
\text { cation }\end{array}$} \\
\hline & & & $\begin{array}{l}\text { The } \\
\text { average }\end{array}$ & $\begin{array}{l}\text { The } \\
\text { standard } \\
\text { deviation }\end{array}$ & $\begin{array}{l}\text { The } \\
\text { average }\end{array}$ & $\begin{array}{l}\text { The } \\
\text { standard } \\
\text { deviation }\end{array}$ & & $\begin{array}{l}\text { The } \\
\text { average }\end{array}$ & $\begin{array}{l}\text { The } \\
\text { standard } \\
\text { deviation }\end{array}$ & $\begin{array}{l}\text { The } \\
\text { average }\end{array}$ & $\begin{array}{l}\text { The } \\
\text { standard } \\
\text { deviation }\end{array}$ & \\
\hline \multirow{6}{*}{$\begin{array}{l}\text { Sensory } \\
\text { processing }\end{array}$} & \multirow{2}{*}{$\begin{array}{l}\text { Auditory } \\
\text { processing }\end{array}$} & $\begin{array}{l}\text { Before } \\
\text { the test }\end{array}$ & 24.27 & 0.90 & 24.23 & 0.85 & 0.21 & 21.76 & 2.73 & 20.33 & 2.58 & 1.52 \\
\hline & & $\begin{array}{l}\text { After the } \\
\text { test }\end{array}$ & 31.53 & 1.71 & 31.32 & 1.61 & 0.71 & 26.76 & 1.20 & 26.20 & 1.42 & 1.22 \\
\hline & \multirow{2}{*}{$\begin{array}{l}\text { Visual } \\
\text { processing }\end{array}$} & $\begin{array}{l}\text { Before } \\
\text { the test }\end{array}$ & 27.02 & 0.87 & 26.78 & 1.22 & 1.20 & 24.65 & 2.18 & 24.73 & 1.28 & -0.13 \\
\hline & & $\begin{array}{l}\text { After the } \\
\text { test }\end{array}$ & 29.65 & 0.86 & 28.92 & 2.02 & $2.59^{*}$ & 28.06 & 2.38 & 26.80 & 1.57 & 1.74 \\
\hline & \multirow{2}{*}{$\begin{array}{l}\text { Tactile } \\
\text { processing }\end{array}$} & $\begin{array}{l}\text { Before } \\
\text { the test }\end{array}$ & 60.17 & 2.09 & 60.06 & 2.24 & 0.95 & 50.35 & 3.87 & 50.53 & 3.83 & -0.13 \\
\hline & & $\begin{array}{l}\text { After the } \\
\text { test }\end{array}$ & 63.07 & 2.68 & 62.70 & 2.85 & 0.73 & 62.94 & 3.29 & 60.73 & 2.71 & $2.06^{\star}$ \\
\hline \multirow{4}{*}{$\begin{array}{l}\text { Learning } \\
\text { behavior }\end{array}$} & \multirow{2}{*}{ Study habits } & $\begin{array}{l}\text { Before } \\
\text { the test }\end{array}$ & 15.72 & 1.32 & 15.72 & 1.56 & 0.00 & 12.00 & 1.32 & 11.80 & 1.32 & 0.43 \\
\hline & & $\begin{array}{l}\text { After the } \\
\text { test }\end{array}$ & 21.98 & 1.33 & 21.07 & 2.49 & $2.51^{\star}$ & 11.94 & 1.56 & 12.07 & 1.94 & -0.20 \\
\hline & \multirow{2}{*}{$\begin{array}{l}\text { Academic } \\
\text { performance }\end{array}$} & $\begin{array}{l}\text { Before } \\
\text { the test }\end{array}$ & 19.15 & 1.64 & 19.30 & 1.74 & -0.49 & 10.47 & 0.80 & 11.07 & 1.10 & -1.77 \\
\hline & & $\begin{array}{l}\text { After the } \\
\text { test }\end{array}$ & 22.85 & 0.76 & 22.77 & 0.70 & 0.63 & 11.53 & 1.81 & 11.07 & 1.10 & 0.86 \\
\hline
\end{tabular}

${ }^{\star} \mathrm{P}<.05$. 
(variable), indicates that ASD children touch processing reached a significantly higher level ( $\mathrm{F}$ value of $\mathrm{F}=5.04, \mathrm{p}<$. 05). In the post hoc group and for ASD children, touch is found after processing measured the average of the experimental group and control group, and it showed they are not the same. The control group after measuring shows an average of 60.73 , the experimental group after the measured averages is 62.94 . This speculates that ASD children in the touch group made significant additional progress, It is inferred that the children with ASD group benefited from the tactile processing stimuli associated with the teaching method of FigureNotes.

\section{Sensory processing and learning behavior records were analyzed in general infant group and ASD infant group}

According to the data in Table 5 to Table 7, the scores of visual processing and the learning habits of children in the experimental group were higher than those in the general control group, and the scores of tactile processing of children in the experimental group were higher than those in the ASD control group. It is worth further noting that analysis of the learning process associated with the teaching method concludes that it has its own effects. The following is the observation record analysis of the study for 16 weeks: the original score of auditory processing is interpreted as "impaired functional performance" and the value is $8-25$, indicating problems in auditory processing; The value of "edge (or marginal) functional performance" is 26-29, indicating suspected auditory processing problems; The value of "normal functional performance" is 30-40, indicating normal auditory sensory processing. The original score of visual processing was interpreted as "performance of dysfunction" and the value was 9-26, indicating problems in visual sensory processing. The value of "edge functional performance" is 27-31, indicating suspected problems in visual sensory processing; The value of "normal functional performance" is $32-45$, indicating normal visual and sensory processing. The original score of tactile processing was interpreted as "dysfunction performance" and the value was 18-64, indicating that there were problems in tactile sensory processing. The value of "edge functional performance" is 65-72, indicating suspected problems with tactile sensation processing; A "normal functional performance" value of 73-90 indicates normal tactile sensory processing.

\section{Analysis of sensory processing records in the general children group}

The Teaching Method of Image Musical Notes Involves the Analysis of Auditory Processing in Children

Figure 2 shows an improvement of 7.09 points (31.32-24.23) in the general child control group and 7.26 points (31.5324.27 ) in the general child control group, indicating that the scores of the general child control group show a positive growth trend. The pre-test results are based on the impaired functional performance, while the post-test results show the normal functional performance. According to table 6, there was no significant difference in auditory processing $(\mathrm{F}=.53$, $\mathrm{p}>$.05), indicating that although the auditory processing of the general children group showed growth in the study, the progress was not up to the statistical level This also indicated that the interventional image note music teaching method had no obvious effect on the auditory processing of the general children. The following is an analysis of the observations and records of auditory processing in the general infant group.

1. Analysis of learning records before auditory processing in general children group:

A. Initial response to class: What color is this? No reaction (G1-T-57-SP_L-1071121). Look at the keyboard color paper with no response (G2-T-61SP_L-1071121).

B. Focus only on other things in the classroom context: clap your hands when instructed to stop (G1-T-42SP_L-1071121). No response from the back of the classroom (G1-O-39-SP_L-1071121) while singing the welcome song.

Table 6: Abstract of single-factor covariate analysis of "sensory processing" and "learning Behavior" in the general infant group

\begin{tabular}{|c|c|c|c|c|c|c|}
\hline & Source & SS & $d f$ & MS & $F$ & Post hoc \\
\hline \multicolumn{7}{|l|}{ Sensory processing } \\
\hline & $\begin{array}{l}\text { Auditory } \\
\text { processing }\end{array}$ & 1.47 & 1 & 1.47 & 0.53 & \\
\hline & Visual processing & 18.78 & 1 & 18.78 & $7.99^{* *}$ & $\begin{array}{l}\text { The experimental } \\
\text { group. The contro } \\
\text { group }\end{array}$ \\
\hline & Tactile processing & 3.19 & 1 & 3.19 & 0.45 & \\
\hline \multicolumn{7}{|l|}{ Learning behavior } \\
\hline & Study habits & 25.21 & 1 & 25.21 & $6.28^{*}$ & \\
\hline & $\begin{array}{l}\text { Academic } \\
\text { performance }\end{array}$ & 0.19 & 1 & 0.19 & 0.36 & \\
\hline
\end{tabular}

$* \mathrm{P}<.05 ., \quad * * \mathrm{P}<.01$. 
Table 7: Abstract of single-factor covariate analysis of "sensory processing" and "learning Behavior" in children with ASD

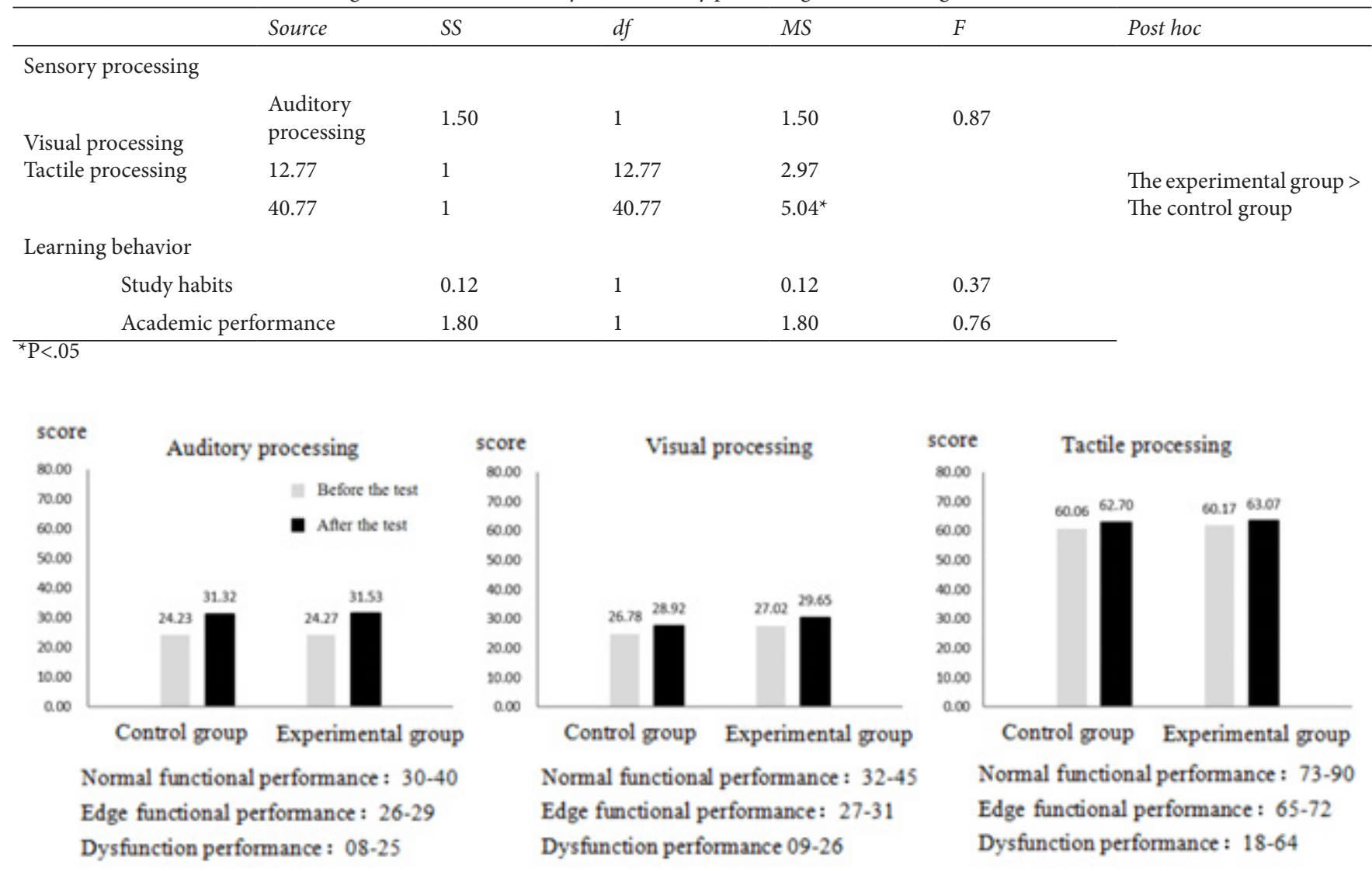

Fig. 2: Sensory processing of children in general

2. Analysis of learning records after auditory processing in general children group:

A. Show correct instructions: hold the black hand bell and shake it (G1-T-17-SP_L-1070123) as instructed. Perform the correct instructions, such as pulling the red expansion band (G2-O-80-SP_L-1070123).

B. Action with music: Clap your hands with blue lights (G2-O-99-SP_L-1070123). Hold the bell and stop (G2-T-113-SP_L-1070123). Shake the blue sandbell (G1-T-42-SP_L-1070123).

An Analysis of the Visual Processing of Children involved in the Teaching of FigureNotes

Figure 2 shows 2.14 points (28.92-26.78) progress in the general child control group and 2.63 points (29.65-27.02) progress in the general child control group; this indicates that the control group has grown from impaired function performance to marginal function performance, while the experimental group has slightly increased in marginal function performance. According to Table 6, there was a statistically significant difference in visual processing ( $\mathrm{F}$ $=7.99, \mathrm{P}<.01$ ); this indicates that the visual processing of the general children group presented a positive growth and the improvement score reached a statistically significant difference. It also indicates that the interventional image note music teaching method had a significantly beneficial effect on the visual processing of the general children. The following is an analysis of the observation records of visual processing in the general children group.

3. Analysis of learning records before visual processing in general children groups:

A. Unable to focus on class: When blue lights appear, look only at the back of the room (G1-O-34-SP_V-1071121). Looking at the cabinet at the back of the room (G2-O93-SP_V-1071121) while randomly changing the color of light-sensitive light. There was no reaction when looking at the color graphics of the keyboard (G2-T101-SP_V-1071121).

B. Show imitation behavior: Watch other children take a gray ball and change the black into gray (G2-T-87SP_V-1071121). Watch other kids holding the gray ball before holding the gray ball (G1-T-41-SP_V-1071121). It is necessary to observe the performance of peers to make correct instruction actions (G1-O-01SP_V-1071121). 
C. Learning process should be reminded: 3 points and assistance are needed to find the corresponding color (G2-T-81-SP_V-1071121).

4. Analysis of learning records after visual processing in general children group:

A. Make the correct command action: it will find the keys corresponding to the black keyboard (G1-T-19SP_V-1070123). The corresponding map card (G1-O33-SP_V-1070123) will be searched sequentially. G1 - O - 55 - SP_V - 1070123). Can play on corresponding keys (G1-T-12-SP_V-1070123). Find the right color beat rhythm (G1-T-60-SP_V-1070123). Find the keys and play them in gray (G1-O-57-SP_V-1070123).

\section{An Analysis of Touch Processing in Children by Figurenotes} Instruction

Figure 2 shows the progress of the general child control group of 2.64 points (62.70-60.06) and the general child control group of 2.9 points (63.07-60.17), indicating that both groups of children have an improvement trend in the performance of impaired functions. The comparison table 6 found no significant difference in touch processing $(\mathrm{F}=.45, \mathrm{p}>.05)$, indicating that although the touch processing in the general children's group grew during the study, it did not reach the statistical level due to the experimental intervention, which also indicated that the interventional FigureNotes teaching method had no beneficial effect on the touch processing in the general children's group. The following is an analysis of the observation records of touch processing in the general children group.

1 Analysis of learning records of tactile and sensory abilities before testing in the general children group:

A. Unable to display correct instructions: unable to press Do and Re (G1-T-39-SP_c-1071121). Keep pressing the Do sound (G1-O-53-SP_c-1071121). Cannot play the corresponding key (G2-T-92-SP_C-1070121) according to the specified color. Keyboard strumming (G2-O-117-SP_C-1071121).
A. Unable to face new stimuli or changes and having negative emotions: not touching the keys and falling down and crying (G1-T-34-SP_C-1071121). Burst into tears when the ball stopped (G1-T-51-SP_C1071121).

2. Analysis of the learning records after the test of the tactile and sensory abilities of the general children group:

A. Accept varied activities: perform corresponding actions with dolls of different colors (G2-O-87SP_C-1070123). Make a head touch and embrace the red doll (G1-T-32-SP_C-1070123).

2. Display correct instruction: continuously eject instruction keyboard (G2-O-96-SP_C-1070123). Look at the specified color and play (G2-T-72-SP_c-1070123). Stretch (G1-O-12SP_C-1070123).

\section{Sensory processing records of children with ASD were analyzed}

\section{An Analysis of the Auditory processing of CHILDREN with ASD involved in FigureNotes instruction}

Figure 3 shows an improvement of 5.87 points (26.20-20.33) for the ASD child control group and 5 points (26.76-21.76) for the ASD child control group. This indicates that the scores of the two groups of children with ASD have grown, with the performance level of dysfunction measured before and the performance of marginal function measured after. According to table 7 , no statistical difference was found in auditory processing $(\mathrm{F}=.87, \mathrm{p}>.05)$, indicating that children with ASD showed growth in auditory processing during the study, and no statistical difference was found from improvement scores. It also indicated that the intervention of using the image, note and music teaching method was not statistically beneficial to the auditory processing of children with ASD. The following is an analysis of the observations and records of auditory processing in children with ASD.

1. Analysis of learning records before auditory processing in children with ASD:

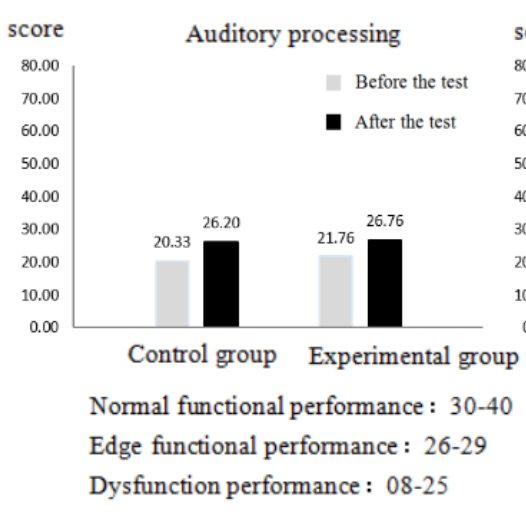

Dysfunction performance : $08-25$

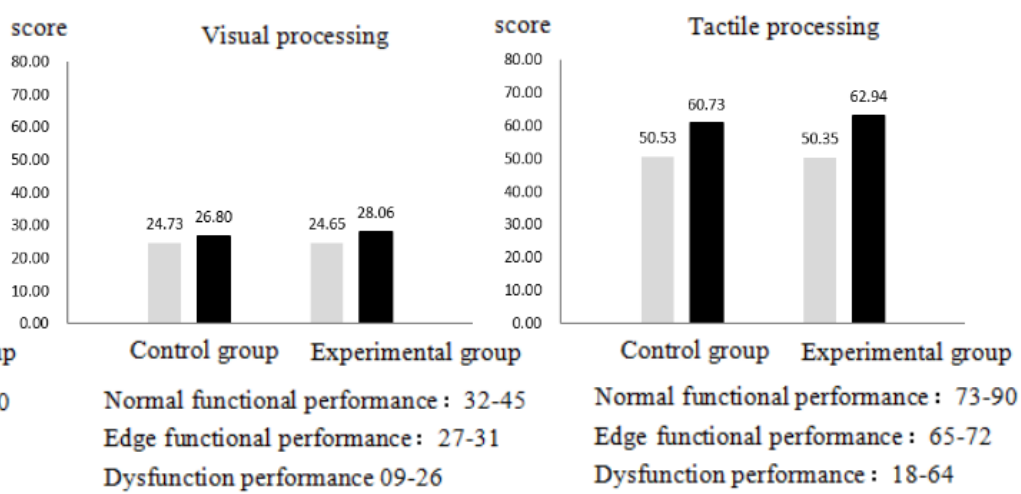

圖3 ASD幼兒組之感覺處理 
A. No response to music class: No response to the floor (S1-T-06-SP_L-1071124; S1 - O - 13 - SP_L - 1071124). Only look at the window (S2-O-30-SP_L-1071124) when playing color matching.

B. The performance rejects or only listens to the fixed string law: the instructor shakes the red sand bell hand not (S2-T-19-SP_L-1071124). Play stop-Go music Cover your ears with your hands and scream to turn the music off (S1-T-01-SP_L-1071124).

C. Performance repeated fixed or the same movement: music stopped and continued shaking the bell for more than 3 minutes (S2-O-21-SP_L-1071124).

2. Analysis of learning records after auditory processing in children with ASD:

A. Correct instruction: Press the keys correctly (S1-T16-SP_L-1070126). Close to the keyboard and listen to yourself pressing the keyboard (S1-O-17SP_L-1070126). Follow the instructions to find the red keyboard and press the keys (S2-T-26-SP_L-1070126). Find the green key and press the correct note (S1-O16-SP_L-1070126).

B. Show rhythmic action: Quickly shake the bell (S1-O16-SP_L-1070126) to a fast rhythm.

\section{An Analysis of the Visual processing of Children with ASD} involved in the Teaching of image Note Music

Figure 3 shows an improvement of 2.07 points (26.80-24.73) in the ASD child control group and 3.41 points (28.06-24.65) in the ASD child control group. This indicates that the scores of the two groups of children with ASD have slightly increased, both of which are changed in the range of impaired functions. The comparison on Table 7 found no significant difference in visual processing ( $\mathrm{F}=2.97, \mathrm{p}>.05)$, indicating that, although visual processing of children with ASD had grown during the intervention, it did not reach the statistical level as a result of the intervention. It also indicated that the interventional FigureNotes teaching method was not proven to be beneficial to visual processing for children with ASD. The following is an analysis of the observations and records of visual processing in children with ASD.

1. Analysis of learning records of children with ASD before visual processing:

A. No reaction to the course: no reaction to finding black balls in different color balls (S1-T-11-SP_V-1071124). When the command holds the black homemade instrument, the respondent only looks at the instrument without any action (S2-T-25-SP_V-1071124).

B. Unable to pair instruction: instructs red ball to pick up gray ball (S1-O-17-SP_V-1071124). Command coffee ball to take gray ball (S2-T-21-SP_V-1071124). Command green ball to take red ball (S1-T-16SP_V-1071124).

C. Hold the fixed color only: hold the black ball (S1-O01-SP_V-1071124).
1. Analysis of learning records after visual processing in children with ASD:

A. Can execute pairing instructions: match colors according to instructions (S1-T-12-SP_V-1070126). Take the instrument as directed (S1-O-03SP_V-1070126). Make the correct matching color (S2-T-22-SP_V-1070126).

B. Show correct instructions: look at the color and find out the correct color keyboard and play it once (S1-O08-SP_V-1070126). Find the relative colors and press the keyboard (S1-T-12-SP_V-1070126).

An analysis of Touch processing in Children with ASD by image Musical instruction

Figure 3 shows the progress of the ASD child control group by 10.2 points (60.73-50.53) and the ASD child control group by 12.59 points (62.94-50.35), indicating that both the ASD child control group and the experimental group showed progress in the performance of impaired functions. The comparison on Table 7 found statistically significant differences in touch processing $(\mathrm{F}=5.04, \mathrm{P}<.05)$, indicating that the touch processing of children in the ASD group had grown from the research process, and the improvement score reached the statistical level. It also indicated that the intervention FigureNotes music teaching method had a beneficial effect on the touch processing of children in ASD. The following is an analysis of the observation records of children with ASD in touch processing.

1. Analysis of learning records of tactile and sensory abilities in children with ASD:

A. Unable to perform command: drop the green pingpong ball on the right hand onto the floor (S1-T07-SP_C-1071124). The black ball takes the red ball (S1-T-01-SP_c-1071124).

A. Seek the same sensory stimulation: repeat pressure Mi or So (S1-O-05-SP_C-1071124). Sandbell to ear for 3 minutes (S1-O-02-SP_C-1071124). Listen for repeat sounds (S1-T-17-SP_L-1071124).

A. Tactile defense: Shake your head back when the red ball meets (S1-T-11-SP_C-1071124) Command right hand raised to immediately redraw in fist shape (S1-O-14-SP_C-1071124). Turn off the music near the $\mathrm{CD}$, meaning don't listen (S1-T-17SP_L-1071124). Unwilling to touch the keys (S1-O-16SP_c-1071124).

2. Analysis of the learning records after testing the tactile and sensory abilities of children in ASD group:

A. Tactile stimulation acceptable: Sand bells can be rolled along the body with music (S1-T-07-SP_C-1070126). Blue wrist bell can be placed on the right hand and shaking sound (S1-T-02-SP_C-1070126). Beat the red board to the music (S1-T-12-SP_C-1070126). 

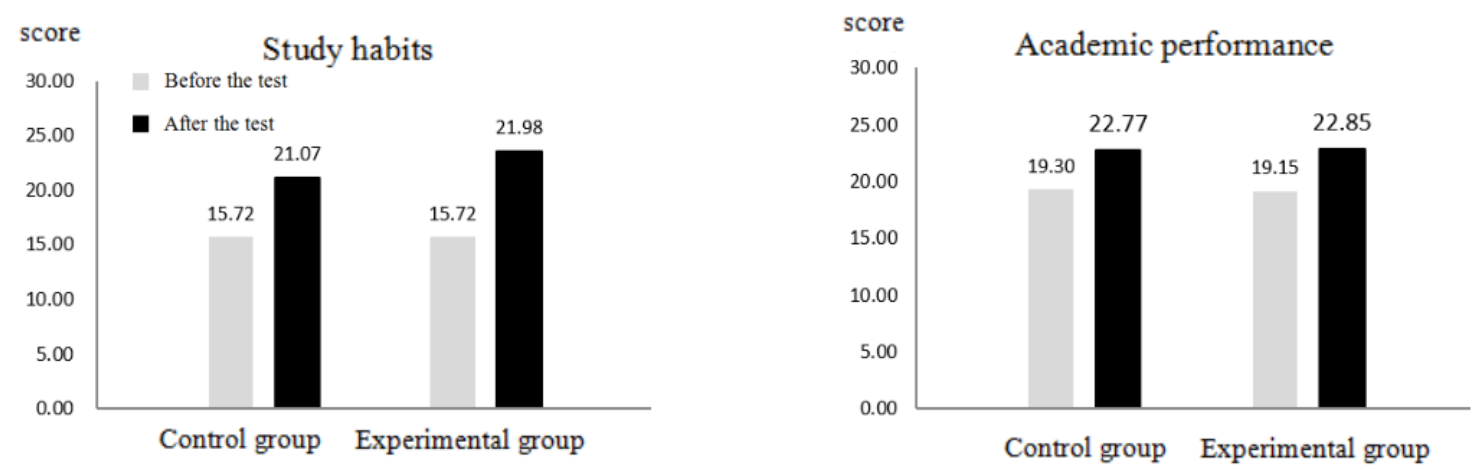

Fig. 4: Learning behavior of children in the general group.

B Promotes visual and motor coordination: can touch command yellow ball (S1-O-10-SP_C-1070126). Can touch a yellow ball and wave (S1-T-12-SP_C-1070126). Imitate music stop lollipop drum with high or low movements (S1-O-06-SP_C-1070126; S1 - O - 09 - SP_C 1070126; S1 - O - 14 - SP_C - 1070126). Follow the music up, down, left and right (S1-O-10-SP_C-1070126).

\section{Record Analysis of Learning Behavior in General infant Group}

\section{An Analysis of the Learning Habits of Children in General}

Figure 4 shows that the average pre-test score of the general child control group is 15.72 points, and the average post-test score is 21.07 points, with an increase of 5.35 points. The average pre-test score of the general child control group is 15.72 points, and the average post-test score is 21.98 points, with an increase of 6.26 points. This shows that the learning habits of the general child control group show a growing trend. According to Table 6 , there were statistically significant differences in learning habits $(\mathrm{F}=6.28, \mathrm{P}<.05)$, indicating that the teaching method of intervening image note music could improve the learning habits of ordinary children. The following is an analysis of the observation records of learning habits in the general children group.

1. Analysis of Learning Records of General Children's Learning Habits Before Testing

A. Inability to focus instructions: Grab the ball after 30 seconds by clapping (G1-O-32-LB_H-1071121). No follow instruction (G1-T-11-1B_H-1071121). No expressive rhythm (G2-T-107-LB_H-1071121).

B. Mime without observation: Clap only when reminded (G2-O-108-LB_H-1071121). Only touch the ball without clapping (G2-T-77-1B_H-1071121).

2. Analysis of learning records after testing the learning habits of general children groups:

A. Focused instruction: Can imitate clapping (G2-T83-1B_H-1070123). Act on the color card (G1-O-57LB_H-1070123, G1-T-02-1B_H-1070123).
B. Do correct commands and imitate actions: steady clap (G2-O-62-SP_C-1070126). Steady beat on the lollipop drum (G1-O-07-SP_C-1070126). Play the correct tone (G2-O-106-1B_H-1070123) as indicated on the chart card. Imitate high and low movements (G1-O-17SP_C-1070126).

An Analysis of the Learning Performance of Children in General involved in the Teaching of FigureNotes

As an infant, Figure 4 appears in the control group before the measured averages of 19.30 points, after measuring the growth to average 22.77 points, as an infant, increased 3.47 points, development and change of the experimental group before the measured averages of 19.15 points, after growth to average 22.85 points, after intervention to intervene before the development and changes of increased 3.7 points, as an infant, according to the control group and experimental group learning performance showed a trend of growth. According to table 6 , no significant difference was found in the learning performance results $(\mathrm{F}=.36, \mathrm{p}>.05)$, indicating that the interventional FigureNotes music teaching method did not improve the learning performance of ordinary children. The following is the study of the general infant group learning performance observation records analysis.

1. Analysis of learning records before testing the learning performance of general child groups:

A. Imitate peers: Look at other children before they move (G2-T-101-LB_P-1071121). Imitate students (G1-T-15LB_P-1071121, G2-O-74-1B_p-1071121).

B. Rely on reminders to represent instructions: clap before reminding (G2-T-93-LB_P-1071121). Don't act until the instructor reminds you (G1-O-37-1B_P-1071121).

2. Analysis of learning records after testing the learning performance of general child groups:

A. Active performance instruction: Look at the clapper in blue table tennis (G2-O-102-LB_P-1071121). Find the blue ball to complete the command (G1-T-121B_p-1070123). Finish playing by looking at the 

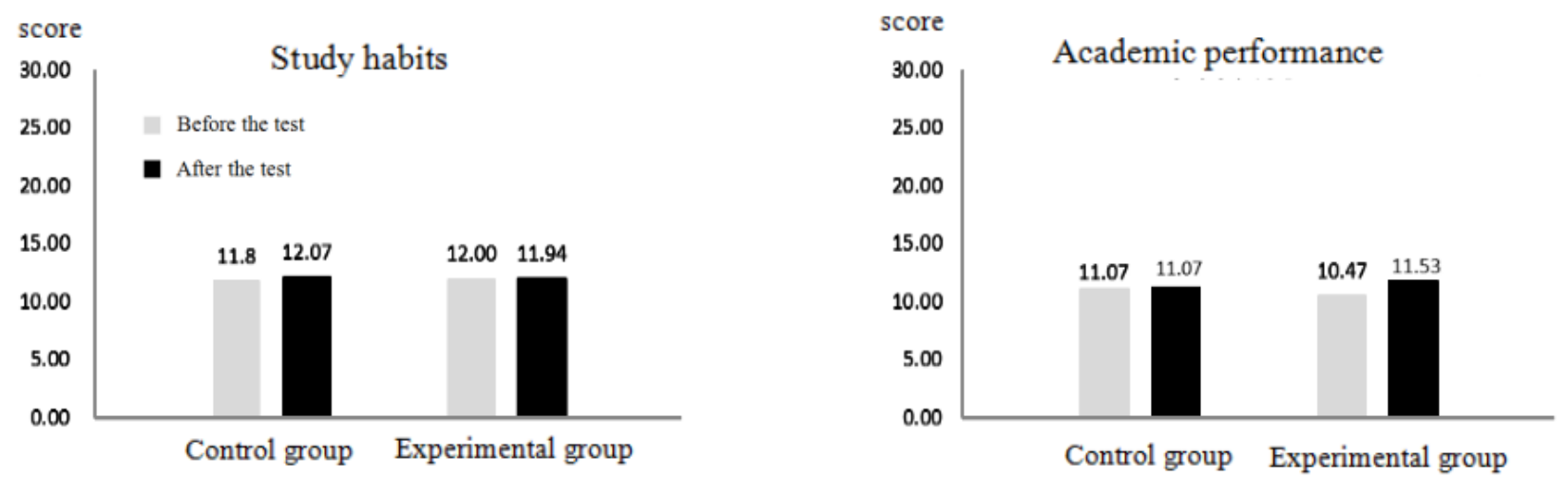

Fig. 5: Learning behavior of children with ASD.

picture card (G2-T-118-1B_P-1070123). Jump into the white hula hoop at the command (G2-O-67-1B P-1070123).

\section{Record analysis of learning behavior in children with ASD \\ An Analysis of the Learning Habits of Children with ASD involved in the Teaching of FigureNotes}

Figure 5 shows that the average pre-test score of the ASD child control group was 11.80 and the average post-test score was 12.07, an increase of .27. The pre-test average of the ASD children in the experimental group was 12.00 points and the post-test average was 11.94 points, slightly lower than that of the experimental group. According to table 7, there was no significant difference in learning habits $(\mathrm{F}=.37, \mathrm{p}>.05)$. It is speculated that the interventional FigureNotes music teaching method could not improve the learning habits of children with ASD. The following is an analysis of the observation records of learning habits of children with ASD.

1. Analysis of learning records of ASD children's learning habits tested before:

A. Unable to focus on command: Ask, "Black?", shake hands and ask again without response (S1-T-011B_H-1071124). Shake hands and ask no response (S1-O-13-1B_H-1071124).

B. Touch defense: Look out of the window and listen to the sound of cars for 2 minutes (S1-T-09-LB_H-1071124). Look at the command card. When you hear the tone, step back and wave your hand to indicate that you should stop playing (S1-O-04-1B_H-1071124).

2. Analysis of learning records after learning habits test in CHILDREN with ASD:

A. Instruction: play the corresponding keys according to the color (S1-T-12-LB_H-1070126). Get the correct blue ping-pong ball (S1-O-16-lB_H-1070126).

B. After 2 attempts, press to the correct Do sound (S2-O26-1B_H-1070126). Hold the gray ball correctly after reminding (S2-T-32-1B_H-1070126).
An Analysis of the Learning Performance of Children with ASD involved in FigureNote instruction

Figure 5 shows the average score of pre-test and post-test in the ASD child control group of 11.07, showing a flat performance. The average pre-test score and post-test score of the ASD child treatment group were 10.47 points and 11.53 points respectively, with a slight growth of 1.06 points, indicating that the learning performance of the ASD child control group was stable and the learning performance of the ASD child treatment group was slightly improved. According to table 7, there was no significant difference in learning performance $(F=.76, p>.05)$, so it is speculated that the interventional FigureNotes music teaching method did not improve the learning performance of children with ASD. The following is the observation and analysis of the learning performance of children with ASD.

1. Analysis of learning Records before testing of learning Performance of children with ASD:

A. Repetitive or stereotyped behaviors occur: after changing the red keyboard, press the gray keyboard 2 times (S1-T-01-LB_P-1071124). Ignoring instructions, keep typing the grey keyboard (S1-O-07-1B_P-1071124).

B. Dependent assistance instruction: press the red keyboard only when prompted by the teacher (S2-O19-1B_P-1071124, S2-O-29-1B_P-1071124). Turn your head to the teacher (S1-T-17-1B_P-1071124).

1. Analysis of learning records after learning Performance test in ASD children group:

A. Show correct instructions: use the index finger to find the correct key and press (S1-O-03-lB_P-1070126). Find the correct keys according to the instruction color (S1-T-07-LB_P-1070126; S2 - O - 27 - LB_P - 1070126). Color pair presses the correct blue key (S1-T-06LB_P-1070126).

\section{Comprehensive discussion}

The purpose of this study is to explore the effect of FigureNotes music teaching on children's sensory processing and learning 
behavior, and the results show that image note music teaching is beneficial to children's sensory processing and learning behavior, as discussed below.

\section{The Teaching Method of FigureNotes can Improve the Visual Processing and Learning Habits of Preschool Children}

Study found that accepting image notes music teaching preschool children generally feel - more alert and balanced, an observation of after processing and learning behavior test score higher than the previous test score, that step in FigureNotes the sense of music teaching of preschool children generally has effect and learning behavior, this result is similar to [33] put forward the argument, that image notes music teaching method can improve learners' learning motivation. The results of the study also confirmed that FigureNotes and music teaching method could improve the visual processing and learning habits of ordinary children. It was observed? that the pre-school children were able to match colors and shapes in the course. Good use of visual processing is helpful for immediate feedback and execution of correct instructions (G1-O-33SP_v-1070123, G1-O-55-SP_V-1070123, G1-T-19-SP_V-1070123, G1-O-12-SP_V-1070123, G1-O-57-SP_V-1070123, G1-T-60SP_V-1070123). In addition, it is speculated that the reason for the effectiveness of FigureNotes music teaching method on learning habits may be that preschool children generally focus on the course content or command signals during the learning process, which is conducive to correct imitation of instructions and actions (G1-T-02-LB_H-1070123, G1-O57-LB_H-1070123). For this reason, the study confirms that the teaching method of FigureNotes is helpful to improve the general children's visual sense of sensory processing and learning habits with learning behaviors.

\section{FigureNotes Music Teaching can help Touch Processing in Preschool Children with Autism Spectrum Disorder}

Studies have found that the teaching method of FigureNotes for children with ASD is effective in sensory processing, which is conducive to the improved performance level of music for patients with special needs [36,37.40-42]. It also proves that the teaching method of FigureNotes can be used as an effective learning aid [37,77]. According to the observational data, ASD children showed no reaction at the beginning of the course [(S1-T-06-SP_L-1071124, S1-O-13-SP_L-1071124)], and no concentration [(S1-T-01-LB_H-1071124, S1-O13-LB_H-1071124)]. There were repeated behaviors [(S1-T-01-LB_P-1071124, S1-O-02-SP_C-1071124, S1-O-05SP_C-1071124, S1-O-07-LB_P-1071124)], and tactile defenses [(S1-O-16-SP_C-1071124, S1-T-09-LB_H-1071124, S1-T-11SP_C-1071124,S1-O-14-SP_C-1071124,S1-T-17-SP_L-1071124)] that occured as the result of accidental or annoying irritation. This finding is similar to that proposed by [18] and [19] that children with ASD have sensory processing problems, such as repetitive behaviors $[58,85]$ and tactile defense in the face of unexpected stimuli $[58,63,64,85]$. In this study, it was found that FigureNotes music teaching method had an effect on the tactile processing of children with ASD, and it is speculated that the presentation of paired images in children with ASD enhanced their limb coordination ability [(S1-O-10-SP_C-1070126, S1-T-12-SP_C-1070126, S1-O-06-SP_C-1070126, S1-O-09-SP_C-1070126, and S1-O14-SP_C-1070126)], and improved tactile processing [(S1-T-02SP_C-1070126, S1-T-07-SP_C-1070126, S1-T-12-SP_C-1070126, S1-O-15-SP_C-1070126)] by hearing the correct tone. For this reason, this study proves that children with ASD can better control their body through music performance [28]. For this reason, this study confirmed that the teaching method of image notes and music can help improve the tactile sensation of sensory processing in children with ASD.

\section{Conclusions and Recommendations}

\section{Conclusion}

FigureNotes music teaching method helps aid preschool children's sensory processing and learning behavior. The results from this study are supported, as an infant, especially FigureNotes music teaching method can improve visual processing of sensory processing and improve learning habits, learning behavior as an infant. FigureNotes music teaching method should be taught through visual color matching the right sound, with tones of color matching, and the actual performance will drop with the expected tone. Making use of FigureNotes music teaching notes will help young children's visual processing and study habits. In addition, the image note music teaching method is helpful to improve the tactile processing of the sensory processing of children with ASD. It is speculated that the extreme sensory response of children with ASD is the result of excessive sensation, excessive focus, or slow reaction, etc. Therefore, making good use of FigureNotes music teaching will help the tactile processing of children with ASD.

\section{Advice}

An emphasis upon the teaching method, FigureNotes, should be based on the needs of learners and should be adjusted at any time to create a new win-win method suitable for each learner $[36,39,42,86]$. HMEAYC also attaches great importance to flexibility adjustment according to children's physical and mental development $[26,46,49]$. The teaching idea of the two teaching methods is similar, which is beneficial to the overall development of effective children's music courses. Research implementation for HMEAYC, combining FigureNotes of music teaching results, can improve the visual processing and promote positive study habits. Research suggests planning as an infant. Preschool music can make use of visual matching 
when teaching, by imitating instruction and developing an understanding of the learning effect. Action performance as an infant, helps to promote continuous learning motivation. The study also found that the image music teaching method can improve the tactile processing of children with ASD. It is suggested to design the teaching strategy of the music course for children with ASD, in addition to making good use of the auxiliary tools. It can also be combined with the sensory stimulation, so as to enhance the learning motivation of children with ASD. To this end, the results of this study confirm that it is meaningful to generally implement FigureNotes music teaching method in Taiwan to assist the sensory processing and learning behavior of preschool general children and ASD children. It is suggested that in future studies, children of different ages and with different special needs of preschool can be further analyzed, so as to collect more information, compare and analyze them, and understand the overall learning effect of the implementation of FigureNotes music teaching on preschool children. Due to the limitations of the number of subjects and control conditions, it is suggested that in the future, in addition to expanding the number of participants in the study, subjects in different fields can also be added to continuously explore the effectiveness of implementing the teaching method of image musical notes. In the end, the qualitative and quantitative data are collected simultaneously, and the quality-oriented parallel research design will be worthy of reference for the future research in the design of music teaching and special education.

\section{References}

Molnar-Szakacs, I.; Overy, K. Music and mirror neurons: from motion to 'e'motion. Social Cognitive and Affective Neuroscience, 2006. 1(3), 235-241. doi.org/10.1093/scan/nsl029

Tillmann, B. Pitch processing in music and speech. Acoustics Australia, 2014. 42 (2), 124-130.

Brandt, P. Music and the abstract mind. Journal of Music and Meaning, 2008. 7(3), 1-7.

DeBedout, J. K.; Worden, M. C. Motivators for children with severe intellectual disabilities in the self-contained classroom: A movement analysis. Journal of Music Therapy, 2006. 43(2), 123-135. https://doi.org/10.1093/jmt/43.2.123

Perrachione, T. K.; Fedorenko, E. G.; Vinke, L.; Gibson, E.; Dilley, L. C. Evidence for Shared Cognitive Processing of Pitch in Music and Language. PLoS ONE, 2013. 8(8), e73372. https:// doi.org/10.1371/journal.pone.0073372

Schon, D.; Boyer, M.; Moreno, S.; Besson, M.; Peretz, I.; Kolinsky, R. Songs as an aid for language acquisition. Cognition, 2008. 106(2), 975-983. https://doi.org/10.1016/j.cognition.2007.03.005

Steele, C. J.; Bailey, J. A.; Zatorre, R. J.; Penhune, V. B. Early Musical Training and White-Matter Plasticity in the Corpus Callosum: Evidence for a Sensitive Period. Journal of Neuroscience, 2013. 33 (3), 1282-1290. https://doi.org/10.1523/ JNEUROSCI.3578-12.2013

Zalar, K.; Kordes, U.; Sicherl, B. The Role of Children 's Musical Instruments in Communication with Musical Language.
Procedia - Social and Behavioral Sciences, 2015. 197, 13261334.

Francois, C.; Grau-Sanchez, J.; Duarte, E.; Rodriguez-Fornells, A. Musical training as an alternative and effective method for neuro- education and neuro-rehabilitation. Frontiers in Psychology, 2015. 6(475), 1-15. https://doi.org/10.3389/ fpsyg.2015.00475

O'Riordan, M.; Passetti, F. Discrimination in autism within different sensory modalities. Journal of Autism and Developmental Disorders, 2006. 36(5), 665-675. https://doi.org/10.1007/ s10803-006-0106-1

Whipple, C. M.; Gfeller, K.; Driscoll, V.; Oleson, J.; McGregor, K. Do communication disorders extend to musical messages? An answer from children with hearing loss or autism spectrum disorders. Journal of Music Therapy, 2015. 52(1), 78-116. https:// doi.org/10.1109/EMBC.2016.7590696.Upper

Wang, Y. P.; Wang, Z. H.; Cai, Xi. Y. Comparison of sensory integration and perceptual motor training in children with developmental retardation. Journal of the Occupational Therapy Society, 2003. 21, 29-44.

Lin, J.; Lin, Z. Etiology of sensory integration developmental disorder in children. Report of the thematic Research Project, Project 1999. No. : CNCE8803.

Ben-Sasson, A.; Hen, L.; Fluss, R.; Cermak, S. A.; Engel-Yeger, B.; Gal, E. A meta-analysis of sensory modulation symptoms in individuals with autism spectrum disorders. Journal of Autism and Developmental Disorders, 2009. 39(1), 1-11. doi. org/10.1007/s10803-008-0593-3

Dunn, W.; Myles, B. S.; Orr, S. Sensory processing issues associated with Asperger syndrome: A preliminary investigation. American Journal of Occupational Therapy, 2002. 56(1), 97-102. doi.org/10.5014/ajot.56.1.97

Solish, A.; Perry, A.; Minnes, P. Participation of children with and without disabilities in social, recreational and leisure activities. Journal of Applied Research in Intellectual Disabilities, 2010 23(3), 226-236. doi.org/10.1111/j.1468-3148.2009.00525.x

Census and Statistics Division, Ministry of Health and Welfare 2.3.5 The number of persons with physical and mental disorders by category and age [original figures]. (2019). Taken from https:// dep.mohw.gov.tw/DOS/cp-2976-13825-113.html

Tomchek, S. D.; Dunn, W. Sensory processing in children with and without autism : A comparative study using the short sensory profile. American Journal of occupational therapy, 2007. 61(2), 190-200.

Tomchek, S. D.; Huebner, R. A.; Dunn, W. Patterns of sensory processing in children with an autism spectrum disorder. Research in Autism Spectrum Disorders, 2014. 8(9), 1214-1224. https://doi.org/10.1016/j.rasd.2014.06.006

Dunn, W. Sensory processing as an evidence-based practice at school. Physical \& occupational therapy in pediatrics, 2008 28(2), 137-140.

Goods, K. S.; Ishijima, E.; Chang, Y. C.; Kasari, C.Preschool based JASPER intervention in minimally verbal children with Autism: Pilot RCT. Journal of Autism and Developmental Disorders, 2013. 43(5), 1050-1056. https://doi.org/10.1007/ s10803-012-1644-3

Kasari, C.; Gulsrud, A. C.; Wong, C.; Kwon, S.; Locke, J. Randomized controlled caregiver mediated joint engagement intervention for toddlers with autism. Journal of Autism and Developmental 
Disorders, 2010. 40(9), 1045-1056. https://doi.org/10.1007/ s10803-010-0955-5

Petruta-maria, C. The Role of Art and Music Therapy Techniques in the Educational System of Children with Special Problems. Procedia - Social and Behavioral Sciences, 2015. 187, 277-282. https://doi.org/10.1016/j.sbspro.2015.03.052

Wu, H. Y. Autism's Hidden music talents. Journal of Pingtung University of Education, 2007. 73-84.

Heaton, P. Assessing musical skills in autistic children who are not savants. Philosophical Transactions of the Royal Society B: Biological Sciences, 2009. 364(1522), 1443-1447. https://doi. org/10.1098/rstb.2008.0327

Lee, L. Music activities for children with disabilities: an example from Taiwan. In D.VBlair \& K. A.McCord(Eds.), Exceptional music pedagogy for children with exceptionalities: International perspectives. 2016. (pp. 131-153). Oxford University Press.

Li, L. Y. Use of modern technology to develop children's creativity and improve their body movements. Chaoyang Journal of Human Society, 2009. 7, 1-40.

Li, L. Y.; He, H. R. Effects of acoustic beams on communication and motor development in children with special needs. Journal of Educational Science Research, 2018.63, 69-104. Doi: 10.6209/ JORIES.201809_63 (3).

Lee, L.; Ho, H. Exploring Young Children's Communication Development through the Soundbeam Trigger Modes in the 'Holistic Music Educational Approach for Young Children' Programme. Malaysian Journal of Music, 2018. 7, 1-19.

Lee, L.; Li, T. Y. The impact of music activities in a multi-sensory room for children with multiple disabilities on developing positive emotions: A case study. Journal of the European Teacher Education Network, 2016. 11, 1-12.

Mustafa Yeniasır; Burak Gökbulut. "Socio-cultural values provided to pre-school children using traditional children games". Journal for Educators, Teachers and Trainers, 10, 2, 2019, -.

Jian, L. X. Teachers and students visit Finland to introduce European music education. Taken from May 18, 2017. http:// wwwchinatimescom/newspapers/20170518000813-260301

Kaikkonen, M.; Kivijärvi, S. Interaction Creates Learning: Engaging Learners with Special Educational Needs through OrffSchulwerk. Approaches: Music Therapy \& Special Music Education, 2013. 5(2), 132-137.

Poutiainen, A.; Kivijärvi, S.; Kaikkonen, M. Music for All for Music. In K.Tirri \& E.Kuusisto(Eds.), Interaction in Educational Domains 2013. pp. 171-181. Helsinki, Finland: SensePublishers.

Verkasalo, S. Resonaari - Entrepreneur in Special Music Education. In P. Strandman(Ed.), Arts-Health-Entrepreneurship? 2012. pp. 30-33. Helsinki, Finland: A Conference on Arts and Health Projects and Practices.

Ruokonen, I.; Pollari, S.; Kaikkonen, M.; Ruismäki, H. The Resonaari special music centre as the developer of special music education between 1995-2010. Procedia - Social and Behavioral Sciences, 2012. 45, 401-406. doi.org/10.1016/j.sbspro.2012.06.576

Sanderson, T.; Sparkes, P.; Murray, R. MusicSPACE at home : A music tuition model for people on the autism spectrum. Good Autism Practice(GAP), 2013. 14(2), 94-98.

Laes, T.; Schmidt, P. Activism within music education: Working towards inclusion and policy change in the Finnish music school context. British Journal of Music Education, 2016. 33(1), 5-23. doi.org/10.1017/S0265051715000224
Laes, T.; Westerlund, H. Performing disability in music teacher education: Moving beyond inclusion through expanded professionalism. International Journal of Music Education, 2017. 1-13. doi.org/10.1177/0255761417703782

Forsblom A.; Ala-Ruona E. Professional Competences of Music Therapists Working in Post-stroke Rehabilitation. Voices: A World Forum For Music Therapy, 2012. 12(3). Retrieved from https://normt.uib.no/index.php/voices/article/view/647/561)

Hakomäki, H. Storycomposing as a path to a child's inner world: a collaborative music therapy experiment with a child co-researcher. Jyväskylä studies in humanities, 2013. 204.

Tsang, M. H.; Chan, Z. R. Sensory Processing Profile Scale for ages 3 to 10 (Chinese version). Taipei: China Behavioral Sciences Association. (2009).

Lee, L. Theory \& Practice of Music Educational Therapy for Young Children with Disabilities凹A Report of the Industry-University Collaboration Research at Taichung Early Intervention Center, Taiwan Fund for Children and Families(Vol.I, II, III, IX, X). Taiwan: Taiwan Fund for Children and Families. 2012.

Lin, Z. H.; Lin, J. R.; Huang, J. R. Investigation on the causes of vestibular dysfunction in sensory integration disorder: a case study of Tainan, Acta Sinica sinica (Humanities) 2003.29, 507-519

Zeng, M. H. How did this happen to my child? A Hidden disorder: On sensory integration and healing, Medical Education Newsletter, 2004. 28, 93-12.

Bodfish, J. W.; Symons, F. J.; Parker, D. E.; Lewis, M. H. Varieties of repetitive behaviour in autism: comparison to mental retardation. Journal of Autism and Developmental Disorders, 2000. 30(3), 237-243. doi.org/10.1023/A:1005596502855

Christensen, D. L.; Braun, K. V. N.; Baio, J.; Bilder, D.; Charles, J.; Constantino, J. N.; Yeargin-Allsopp, M. Prevalence and characteristics of autism spectrum disorder among children aged 8 years-autism and developmental disabilities monitoring network, 11 sites, United States, 2012. MMWR Surveillance Summaries, 2018. 65(13), 1-39. https://doi. org $/ 10.15585 / \mathrm{mmwr}$.ss6513a1

Lord, C. E. Autism: From research to practice. American Psychologist, 2010. 65(8), 815-826. doi.org/10.1037/0003-066X.65.8.815

Sturm, H.; Fernell, E.; Gillberg, C. Autism spectrum disorders in children with normal intellectual levels: Associated impairments and subgroups. Developmental Medicine and Child Neurology, 2004. 46(7), 444-447.

Srinivasan, S. M.; Bhat, A. N. A review of "music and movement" therapies for children with autism: embodied interventions for multisystem development. Frontiers in Integrative Neuroscience, 2013. 7, 1-21. doi.org/10.3389/fnint.2013.00022

Jiang, Z. X.; Song W. C. Early diagnosis of autism in young children: a review of the literature. Journal of Clinical Psychology, 2005. 2, 1-10. https://doi.org/10.6550/ACP

Zhang, Z. F.; Wu, Y. Y. Early development and current symptoms of Asperger's syndrome and high-functioning autism. Journal of special education studies, 2006. 31,139 -- 164. Doi: 10.6172 / BSE 200609.3101007

Hochhauser, M.; Engel-Yeger, B. Sensory processing abilities and their relation to participation in leisure activities among children with high-functioning autism spectrum disorder(HFASD). Research in Autism Spectrum Disorders, 2010. 4(4), 746-754. doi.org/10.1016/j.rasd.2010.01.015 
Pfeiffer, B.; Kinnealey, M.; Reed, C.; Herzberg, G. Sensory modulation and affective disorders in children and adolescents with Asperger's disorder. American Journal of Occupational Therapy, 2005. 59(3), 335-345. doi.org/10.5014/ajot.59.3.335

Ben-sasson, A.; Cermak, S. A.; Orsmond, G. I.; Tager-flusberg, H.; Carter, A. S.; Kadlec, M. B.; Dunn, W. Extreme sensory modulation behaviors in extreme sensory modulation behaviors in toddlers with autism spectrum disorders. American Journal of Occupational Therapy, 2007.61(5), 584-592. doi.org/10.5014/ ajot.61.5.584

Baranek, G. T.; David, F. J.; Poe, M. D.; Stone, W. L.; Watson, L. R. Sensory experiences questionnaire: discriminating sensory features in young children with autism, developmental delays, and typical development. Journal of Child Psychology and Psychiatry and Allied Disciplines, 2006. 47(6), 591-601. doi. org/10.1111/j.1469-7610.2005.01546.x

Liss, M.; Saulnier, C.; Fein, D.; Kinsbourne, M. Sensory and attention abnormalities in autistic spectrum disorders. Autism, 10(2), 2006. 155-172. doi.org/10.1177/1362361306062021

Potvin, M.-C.; Snider, L.; Prelock, P.; Kehayia, E.; Wood-Dauphinee, S. Recreational participation of children with high functioning autism. Journal of Autism and Developmental Disorders, 2013. 43(2), 445-457. doi.org/10.1007/s10803-012-1589-6

Stephenson, J. Recognition and use of line drawings by children with severe intellectual disabilities: The effects of color and outline shape. Augmentative and Alternative Communication, 2009. 25 (1), 55-67. https://doi.org/10.1080/07434610802602810

Ganz, J. B.; Parker, R.; Benson, J. Impact of the picture exchange communication system: Effects on communication and collateral effects on maladaptive behaviors picture exchange communication and maladaptive behaviors. Augmentative and Alternative Communication, 2009. 25(4), 250-261. https:/doi. org/10.3109/07434610903381111

Ganz, J. B.; Simpson, R. L. Effects on communicative requesting and speech development of the picture exchange communication system in children with characteristics of autism. Journal of Autism and Developmental Disorders, 2004. 34(4), 395-409. https://doi.org/10.1023/B:JADD.0000037416.59095.d7

Jurgens, A.; Anderson, A.; Moore, D. W. The effect of teaching PECS to a child with autism on verbal behaviour, play, and social functioning. Behaviour Change, 2009. 26(1), 66-81. https://doi. org/10.1375/bech.26.1.66
Huang, Z. X. Eye movement was used to investigate the difference of symbol recognition between developmental retardation children and their peers. Journal of Special Education Studies, 2016. 41, 67-98. https://doi.org/10.6172/BSE.201611.4103003

Barker, R. M.; Akaba, S.; Brady, N. C.; Thiemann-Bourque, K. Support for AAC use in preschool; and growth in language skills; for young children with developmental disabilities. Augmentative and Alternative Communication, 2013.29(4), 334-346. https:// doi.org/10.3109/07434618.2013.848933

Brady, N. C.; Storkel, H. L.; Bushnell, P.; Barker, R. M.; Saunders, K.; Daniels, D.; Fleming, K. Investigating a multimodal intervention for children with limited expressive vocabularies associated with autism. American Journal of Speech-Language Pathology, 2015. 24(3), 438-459. https://doi.org/10.1044/2015

Lim, H. A.; Draper, E. The Effects of Music Therapy Incorporated with Applied Behavior Analysis Verbal Behavior Approach for Children with Autism Spectrum Disorders. Journal of Music Therapy, 2011. 48(4), 532-550. https://doi.org/10.1093/ jmt $/ 48.4 .532$

Lu, T. H.; Chen, X. Y. Adaptive Behavior Assessment System, 2nd edition (2-5 for young Children). Taipei: China Behavioral Sciences Association. (2009).

Cai, M. F.; Wu, Y. Y.; Zhuang, H. H. Research on the establishment of a Social Behavior Assessment system for preschool Children. Journal of Special Education Studies, 2014. 39, 1-31. Doi: 10.6172 / BSE. 201407.3902001

Lee, D.; Arthur, I. T.; Morrone, A. S. Using video surveillance footage to support validity of self-reported classroom data. International Journal of Research \& Method in Education, 2017. 40(2), 154-180. doi.org/10.1080/1743727X.2015.1075496

Rosenstein, B. Video use in social science research and program evaluation. International Journal of Qualitative Methods, 2002. $1(3), 22-43$.

Srinivasan, S. M.; Bhat, A. N. A review of "music and movement" therapies for children with autism: embodied interventions for multisystem development. Frontiers in Integrative Neuroscience, 2013. 7, 1-21. https://doi.org/10.3389/fnint.2013.00022

Kivijärvi, S. Project disabled people as musicians: A systemic approach. Procedia-Social and Behavioral Sciences, 2012. 45, 416-427. doi.org/10.1016/j.sbspro.2012.06.578

Laes, T. The(im)possibility of inclusion: reimagining the potentials of democratic inclusion in and through activist music education. Taideyliopiston Sibelius-Akatemia. 2017. 